Virginia Commonwealth University VCU Scholars Compass

2011

\title{
Preparing a Professional Teaching Portfolio for an Art Teaching Position
}

Melanie L. Buffington

Virginia Commonwealth University, mbuffington@vcu.edu

Follow this and additional works at: http://scholarscompass.vcu.edu/arte_pubs

Part of the Art Education Commons

Copyright (C) National Art Education Association (NAEA)

\section{Downloaded from}

http://scholarscompass.vcu.edu/arte_pubs/4

This Article is brought to you for free and open access by the Dept. of Art Education at VCU Scholars Compass. It has been accepted for inclusion in Art Education Publications by an authorized administrator of VCU Scholars Compass. For more information, please contact libcompass@vcu.edu. 


\title{
Preparing a
}

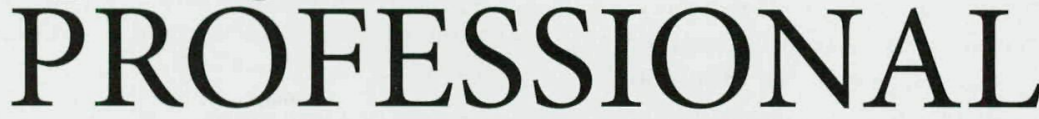

TE

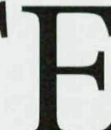

A

(1)

$\mathrm{PO}$
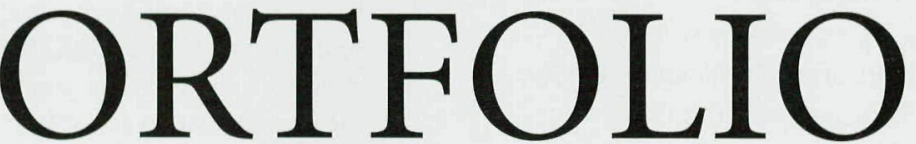

for an Art Teaching Position

\author{
BY MELANIE L. BUFFINGTON
}

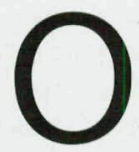

ver time, the idea of bringing a professional teaching portfolio to a job interview has become an expecta-

tion. Preparing these portfolios is a common part of teacher education programs and can be excellent preparation for a job interview. Additionally, teachers who are looking into changing positions will need to prepare a professional portfolio and this process may help them reflect on their practice too. The habits required for creating a professional teaching portfolio-including documenting classroom practices, reflecting on these practices, and organizing this content-are habits that can enhance teaching practice throughout a career.

In my position in a university art education department, I work with preservice teachers as they prepare their professional portfolios. They frequently ask excellent questions and I find that I do not always have the answers to their questions. Though I share my personal experiences with students, it is obvious that my experiences creating a portfolio and using in the job search process are dated. After searching in the literature in our field, I found some recent work on the job search process at various levels (Bain, 2005; Buffington \& Lai, 2006), some work on portfolios in general (Bullock \& Hawk, 2000; Campbell, Cignetti, Melenyzer, Nettles, \& Wyman, 2007; Constantino \& De Lorenzo, 2006; Kimball, 2003; Seldin, 2004; Wyatt \& Looper, 2004), but little that was specific to the creation of professional portfolios for art educators. The many books and articles from general education about professional teaching portfolios address numerous important general concerns. However, to better understand the expectations of professional portfolios in the field of art education, I conducted a survey of art curriculum supervisors who are members of the Supervision and Administration Division of the National Art Education Association to learn about how they use portfolios in the hiring process. Of the 469 members of the Supervision and Administration Division, I received 93 responses to the survey. In this article, I share some suggestions based on the data from the survey and offer advice to job applicants regarding the creation of a professional teaching portfolio.

\section{What is a professional teaching portfolio?}

A professional teaching portfolio is a carefully selected, organized collection of artifacts that show the applicant's abilities in multiple facets of art education. These artifacts provide evidence of knowledge, dispositions, and skills as an art educator (Campbell, et. al, 2007). For art educators, professional portfolios typically contain artifacts that show their credentials as a teacher, their lesson or unit plans, their personal artwork, and their students' artwork. This information is organized into a high-quality binder or another format that allows for some flexibility in adding or removing information. The professional teaching portfolio should showcase the best that an applicant can do, rather than all that the applicant has done. Both the content and the presentation are extremely important. Assembling a high-quality professional teaching portfolio takes a significant
Detail from an image of personal work from a job applicant's portfolio. See page 15. 
amount of time and the process involves reviewing documents and images, selecting the best to use, creating new documents and images, and reformatting existing items to be consistent throughout the portfolio.

\section{Why do I need one?}

Portfolios have become an expected item for art educators to use in the interview process; $89 \%$ of the curriculum supervisors who responded to the survey indicated that they expect an applicant to come to an interview with a teaching portfolio. The other respondents said that though they did not always expect applicants to come to their interviews with a portfolio, that it was certainly an asset to the job applicants if they had one. Using a portfolio in an interview allows applicants the opportunity not just to tell the interviewer about a particularly successful lesson or unit, but also to show the interviewer the lesson or unit plan, images of the artmaking process, the students' finished art, and to explain the assessment. This enables a job applicant to showcase a wide range of abilities and skills relevant to the teaching position.

In addition to meeting the expectation of art supervisors, job applicants also need a professional teaching portfolio because creating it is a meaningful way to reflect on their strengths as teachers and as artists. Additionally, through the process of choosing artifacts and writing captions, job applicants may see connections between their teaching and artmaking that were not previously visible.

\section{What should be in my professional teaching portfolio?}

The documents that are commonly in a teaching portfolio for art educators include a resume, a teaching philosophy, lesson or unit plans, personal artworks, and student artworks. Other items may also be included in a portfolio, but they need to add a significant piece to the picture of a well-prepared art educator. When selecting items for a professional portfolio, it is important to consider, "What does this artifact add to the portfolio that is not already shown?" The best portfolio is not necessarily the longest portfolio. Wyatt and Looper (2004) suggest that the portfolio building process includes four steps: Collecting artifacts, Organizing artifacts, Reflecting on artifacts, and Presenting artifacts. They use the acronym CORP to represent this process and further suggest that portfolios be created with a specific audience in mind.

The curriculum supervisors who responded to the survey indicated that they agree or strongly agree that these items belong in a professional teaching portfolio:

- Resume (99\%)

- Teaching philosophy (97\%)

- Images of student $\operatorname{art}^{1}(96 \%)$

- Lesson plans (95\%)

- Applicant's own artwork (91\%)

- Letters of recommendation (86\%)

- Assessment rubrics (85\%)

- Teaching license (82\%)

- Transcripts (76\%)

- Classroom management plan (68\%)

\section{Credentials}

Credentials consist of the documents that show professional abilities and eligibility for a teaching position. These include a resumé, a teaching philosophy, a teaching certificate or license, and possibly a transcript or test scores. The supervisors who responded to the survey indicated that their preferred length for a resume is between 1 and 2 pages and that a teaching philosophy should be no more than 1 page. It is important to write these documents succinctly and keep them free of jargon. Job applicants should remember that both art educators and generalist educators may be involved in the hiring process and the documents in a portfolio should be meaningful to both of these audiences.

Writing a teaching philosophy can be a challenge. While writing one, job applicants might think about what aspects of education are important and what they do in the classroom to show that. A teaching philosophy should be relatively short, use common educational language, and provide concrete examples of how the philosophy plays out in daily teaching practice. In some districts, a principal will interview job applicants and her/his background may be in science education, special education, or physical education. Thus, it is important that a teaching philosophy explain art education terms (i.e. visual culture or Discipline-Based Art Education [DBAE]) or use terms from general education (i.e. multiculturalism). If an applicant mentions in the philosophy that educational technology is important, the applicant should think about ways to show that throughout the portfolio. This could be through the inclusion of a unit that relates to Web 2.0, involves social media or image-editing software, or includes artists who work with digital technologies. Further, an applicant for an art teaching position could include some of her or his own digital artwork.

\section{Lesson or Unit Plans}

Most educators include 2-3 excellent lesson or unit plans in their portfolios. When selecting which ones to include, it is important to recognize that the choice of lesson or unit plans reflects the applicant's philosophy of education. If an applicant chooses to include a lesson that relates to the elements and principles of design, this is a philosophical statement about what art education is. Lesson or unit plans need to be formatted to fit the portfolio structure and should include images of the teaching and artmaking process throughout the plan document itself.

In order to create a cohesive portfolio, it is a good idea to think about the statement of teaching philosophy and choose lessons or units that show how this philosophy comes to life through classroom practices. For instance, if a philosophy states that cooperative learning and multiculturalism are important and the units this applicant includes in the portfolio relate to students making independent paintings in the style of van Gogh, there is a significant disconnect between what the applicant said was important and what the applicant actually does in the art classroom.

Additionally, it is also important to ensure that the objectives of the lessons or units correlate to the assessment instrument included. This likely requires a unique rubric for each lesson or unit that a job applicant includes in the professional teaching portfolio. During an interview, one curriculum supervisor indicated that when reviewing applicants' unit plans, he always looks for a meaningful big idea or theme, reviews the unit objectives, looks at the assessment rubric to make sure the objectives are being assessed, and looks for images of resulting student art with every unit plan.

When choosing the lesson or unit plans to include, applicants should consider the schools to which they are applying. For instance, if a teacher is interested in applying to a high school and only includes elementary units, this applicant may not appear to be a good fit for the position. Also, if the job is a ceramics position and an applicant includes only 2-D based units, this person also will not appear to be a good 


\section{Unit 1 - Tradition}

"Longevity in Korean Folk Art" Projected \# of Days: 4 days, $45 \mathrm{~min}$ periods

Targeted Student Group: $5^{\text {Th }}$ grade, Suburban

Overview

Through this lesson, the students will learn abour traditional Korean folk art

"Shipjangsengdo" which refers 10 long living symbols: sun, mountain, water, rock, cloud, a pine tree, never dying plant, turte, deer, and crane. After learning abour Korean tradirional folk art, the students will create their own

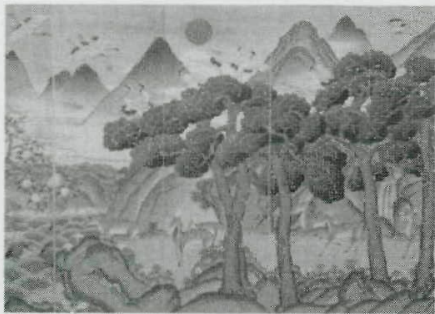

artwork using these symbols and collagraphy techniques. This art process will help students experience collagraphy techniques wich diverse patterns, shapes, lines, and composition in their artwork. Big Idea: Tradition Key Concepts

- A tradition is customs taught by one generation to the next.

Essential Questions:

- What is a tradicion?

- How does a tradition change in different cultures? Unir Objectives

- After discussing about Korean folk art Shipjansengdo, the students will be able to define 10 symbols of longevity in Korean folk art.

- After learning about a collagraphy technique, the students will be able to create collagraphy plates using diverse materials such as paper, string, glue, and fabric.

- After creating collagraphy plates using symbols of longevity, the students will be able to print the collagraphy plates using brayer and printing press.

- After experiencing collagraphy printmaking, the students will be able to identify the difference between painting and prinemaking

\section{Materials and Vocabularies}

- John Biggers' artwork, letter size papers, pencils, erasers, rulers, watercolor, brushes, glues, index cards

- Pattern, symbol, bi-lateral, radial symmetry, complementary, analogous color, resistance, texture, gridding

\section{Process of the lessons}

Step 1

After reviewing the symbols in John Biggers' artwork, the students represented their furure 5 importan values and interests in the form of symbols. Using bi-lateral or radial symmetry which is a form of John Biggers' artwork, the students developed sketches of their furure selves.
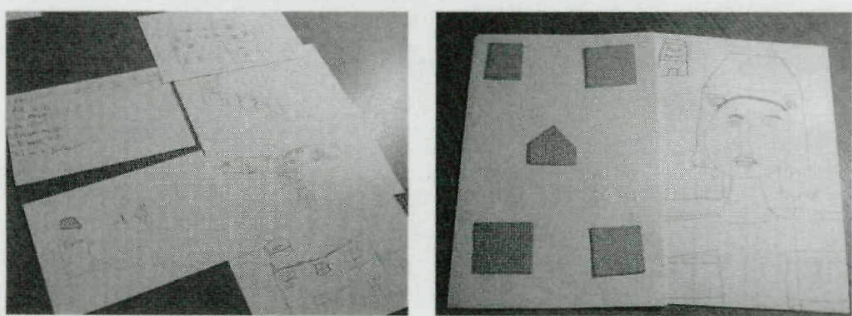

Step 2

The students created physical growth in their own art by using a gridding process. After discussing how new experience can make people grow, the students created diverse lines, patterns, and textures inspired by a new experience using glue.
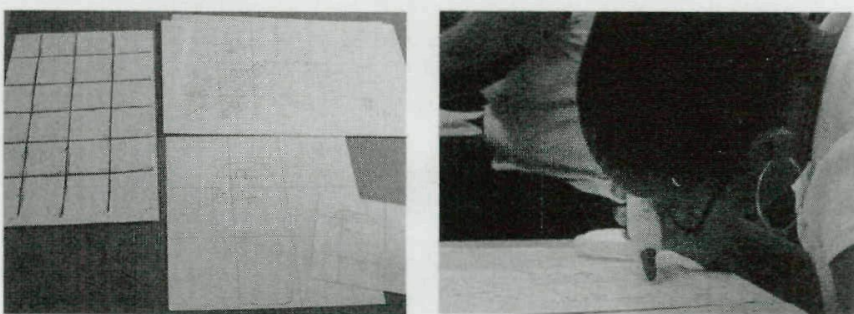

Step 3

The students painted watercolor on the surface with dried glue and candle wax using complementary or analogous color inspired by a positive relationship with someone who might have an effect on their future. The students finished warercolor painting and wrote about their works of art which were related with growth and future selves

3

Examples of how a job applicant reformatted unit plans for her professional teaching portfolio.

Using a portfolio in an interview allows applicants the opportunity not just to tell the interviewer about a particularly successful lesson or unit, but also to show the interviewer the lesson or unit plan, images of the artmaking process, the students' finished art, and to explain the assessment. 


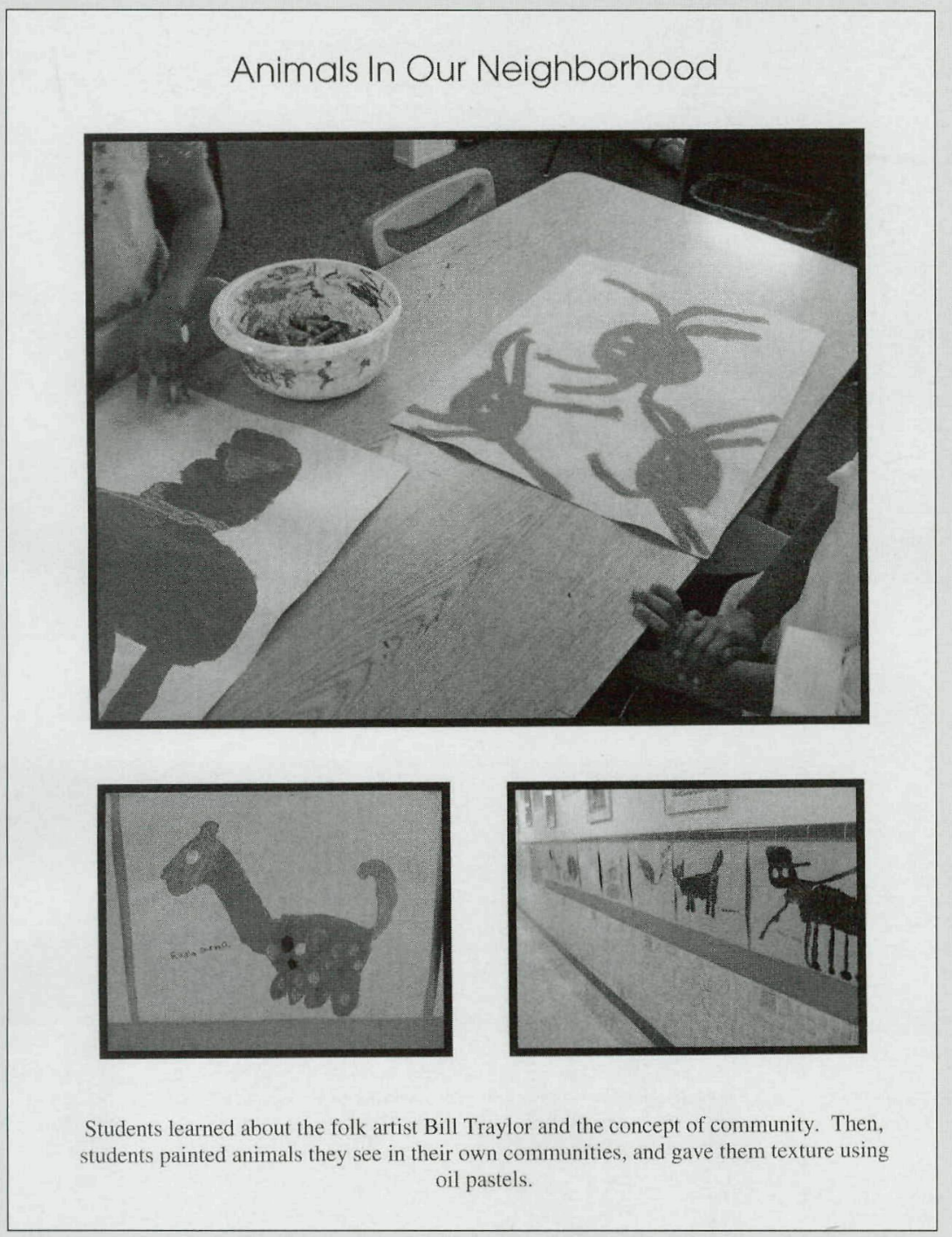

Images of a student work in process, a close-up of a finished work, and a picture of the display of student work in the school. fit. For preservice teachers planning ahead for their job search, it is a good idea to intentionally write lessons and units directed at different levels utilizing different media so they have a selection of high-quality curricula from which to select for their professional teaching portfolio.

\section{Images of Student Art}

It is quite important to showcase in a portfolio what students learned. Images of student work and the process that they utilized to make this art can significantly help in showing their learning. When making selections of student art for a teaching portfolio, include multiple students' work from each unit so that the interviewer can see the range of what students do. Though at one point, the goal may have been for student work to look quite similar, it is now considered a better practice to allow students to make work that is personally meaningful - this likely will look different (Roberts, 2005; Walker, 2001). Also, with each image of student work, include the age of the student, the title of the lesson or unit, a statement about the artmaking process, and a sentence or two about the meaning of the artwork. Think about including images that show the entire artmaking process including students working on their art, the finished pieces, and an exhibition of the work.

\section{Images of Personal Art}

When job applicants select images of their own art to include, it is important to use high-quality images of high-quality artworks. One curriculum supervisor commented that, "If applicants cannot distinguish high and low quality among their own artworks, how can they assess student art?" Keep in mind that the supervisors indicated a strong preference for traditional art materials. Numerous respondents indicated that certain types of artwork made principals uncomfortable and that applicants need to be careful in their image selection. Based upon the survey responses, the curriculum supervisors think that some principals assume that teaching applicants' personal artwork has a direct correlation to the type of art they will teach their students.

As a job applicant, you need to make decisions about how you will handle this situation. Based upon the results of this study, it seems safer to keep nude figure drawings out of a professional teaching portfolio, but applicants needs to decide if a school that would not hire someone who does figure drawing in their own time is a school in which they want to teach. Alternatively, job applicants can create artworks specifically for their portfolio too. If figure drawing is an applicant's emphasis, she or he could make drawings of feet or hands that are less likely to offend. 


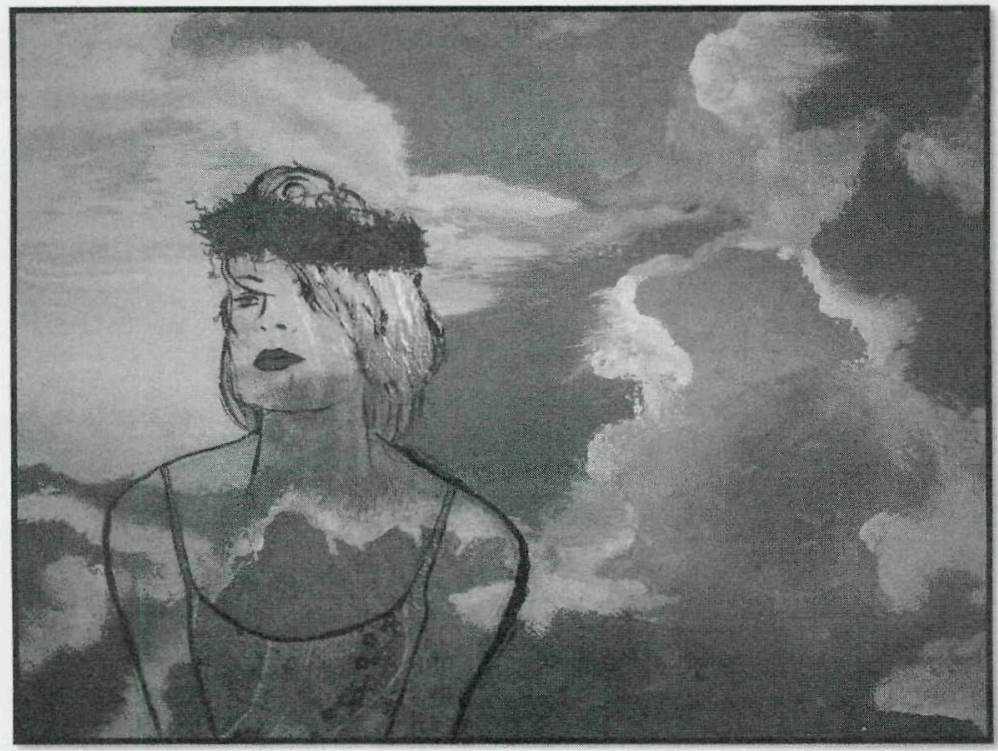

This is an image of personal work from a job applicant's portfolio. What she discusses in her teaching philosophy is reflected throughout the portfolio in her works of art and in the units she chose to include. Further, she used high-quality resumé paper throughout the portfolio and consistently put a black border around each image.

\section{"Girl \#5" \\ Acrylic Paint \\ $18^{\prime \prime} \times 18^{\prime \prime}$ \\ 2009}

This painting is based on a collection of seven mixed media portraits of woman that portray femininity. The common medium includes paint, origami paper, hair pieces or halos, glitter, and found objects. 1 was inspired by the serene expressions on the woman's faces coexisting with landscape backgrounds. The halos and hair pieces praise femininity as a strong peaceful quality. This piece was featured in an art showing of the collection at Ipanema Café in Richmond Virginia in the summer of 200

This is an image of personal artwork from an applicant's portfolio. She explains the work in a short caption and includes close-ups of the work.
Items that art educators may not consider offensive may be offensive to others. For instance, one curriculum supervisor noted that an applicant's metal work made a principal uncomfortable because the principal thought the handmade metal letter opener looked like a weapon. Applicants might include a caption with each image in order to help viewers understand their artwork. The caption should be brief and include the date, title, medium, and a sentence or two about the meaning of the artwork.

When selecting artworks, it is important to show both a breadth of ability as well as depth of ability in at least one medium. I suggest including about 8-10 works of art that include at least 5 different media. Keep in mind that although people who are trained in the visual arts see a difference between a silkscreen, a lithograph, a woodcut print, and a linoleum cut, those outside the arts may perceive these as the same medium of printmaking. When applicants choose artworks for their portfolio, it is helpful to think about how the choice of artwork shows the range of classes that the applicants can teach.

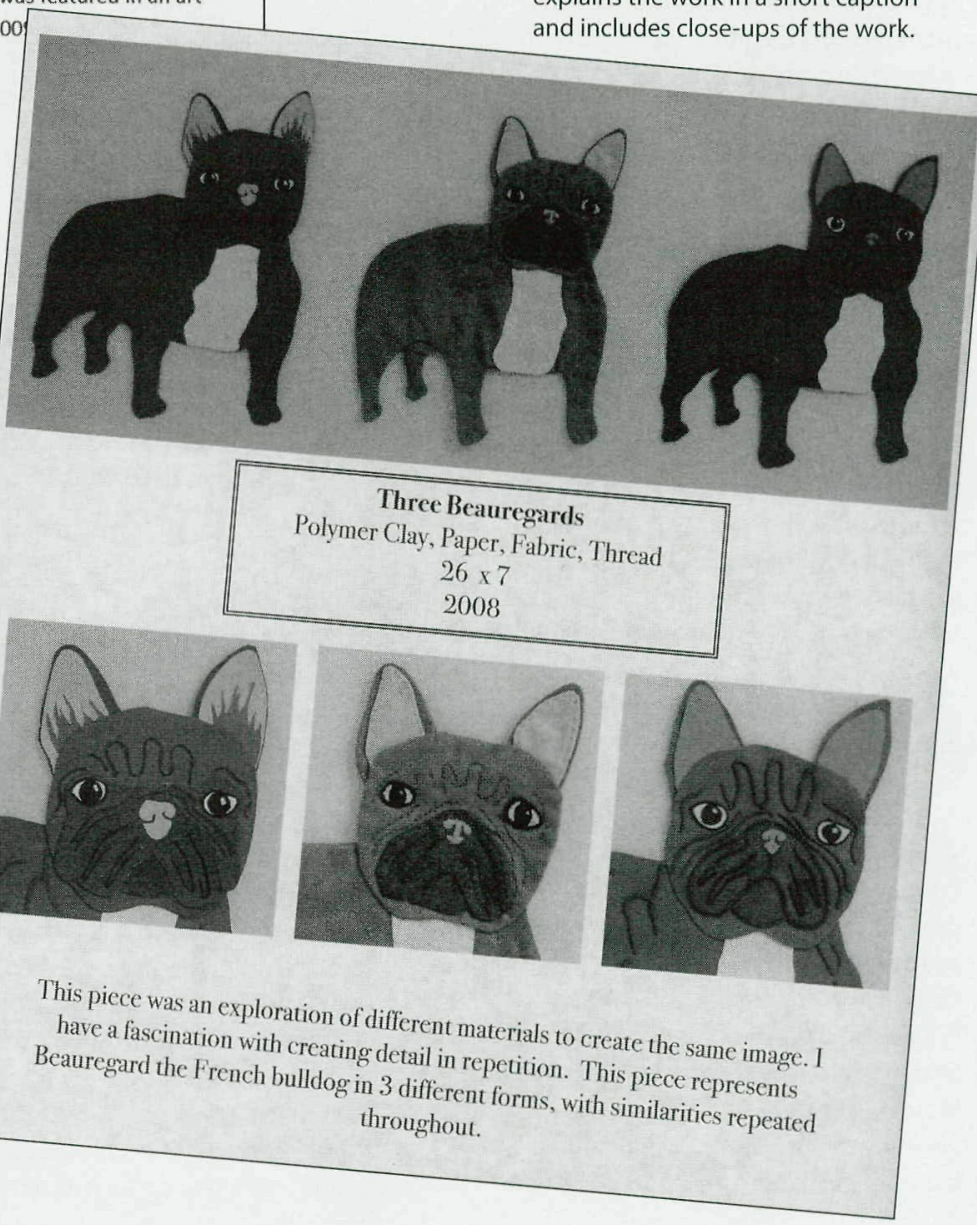




\section{How should I organize the artifacts?}

Organizing the artifacts in a portfolio is as important as selecting the artifacts to include. The portfolio is a tool for principals and curriculum supervisors to assess an applicant's abilities, and it is also a tool for the applicant to guide the direction of the interview. It is important for applicants to be able to find each artifact quickly and easily during the interview so they can do more than answer the questions, but also show the interviewer visual evidence of what they are saying. Thus, the organization of the portfolio is worth careful consideration. One idea that seems to work well for many applicants about to embark on their job search is to create sections based around the various competencies that the portfolio needs to demonstrate. For instance, using section dividers with tabs and breaking the contents of the portfolios into chunks seems to work well as an overall organizational structure. Across all sections of a professional portfolio, an applicant needs to maintain a consistent format of organization. If the first page of one section includes a list of all the artifacts in that section, then each section needs to have a page that lists the artifacts in the section.

\section{How do I use the portfolio in an interview?}

Portfolios can help an applicant during interviews. When asked a common interview question such as, "Tell me about your best unit," an applicant can flip to that section of her or his portfolio and not only tell the interviewer about the unit, but also show the unit plan, images of the students' artmaking process, the rubric or assessment tool, images of students' final artworks, and a reflection. Using the portfolio as a tool can provide applicants with confidence and also help them remember to mention important details during an interview. Applicants for art teaching positions should be prepared to walk a principal or curriculum supervisor through their entire portfolio if that is what the interviewer requests. Before an interview, job applicants should review the school's website and the NAEA Standards on Teacher Preparation and be prepared to address how the artifacts in their portfolio show how they are a good fit for the school's mission, and also have met all the standards of NAEA.

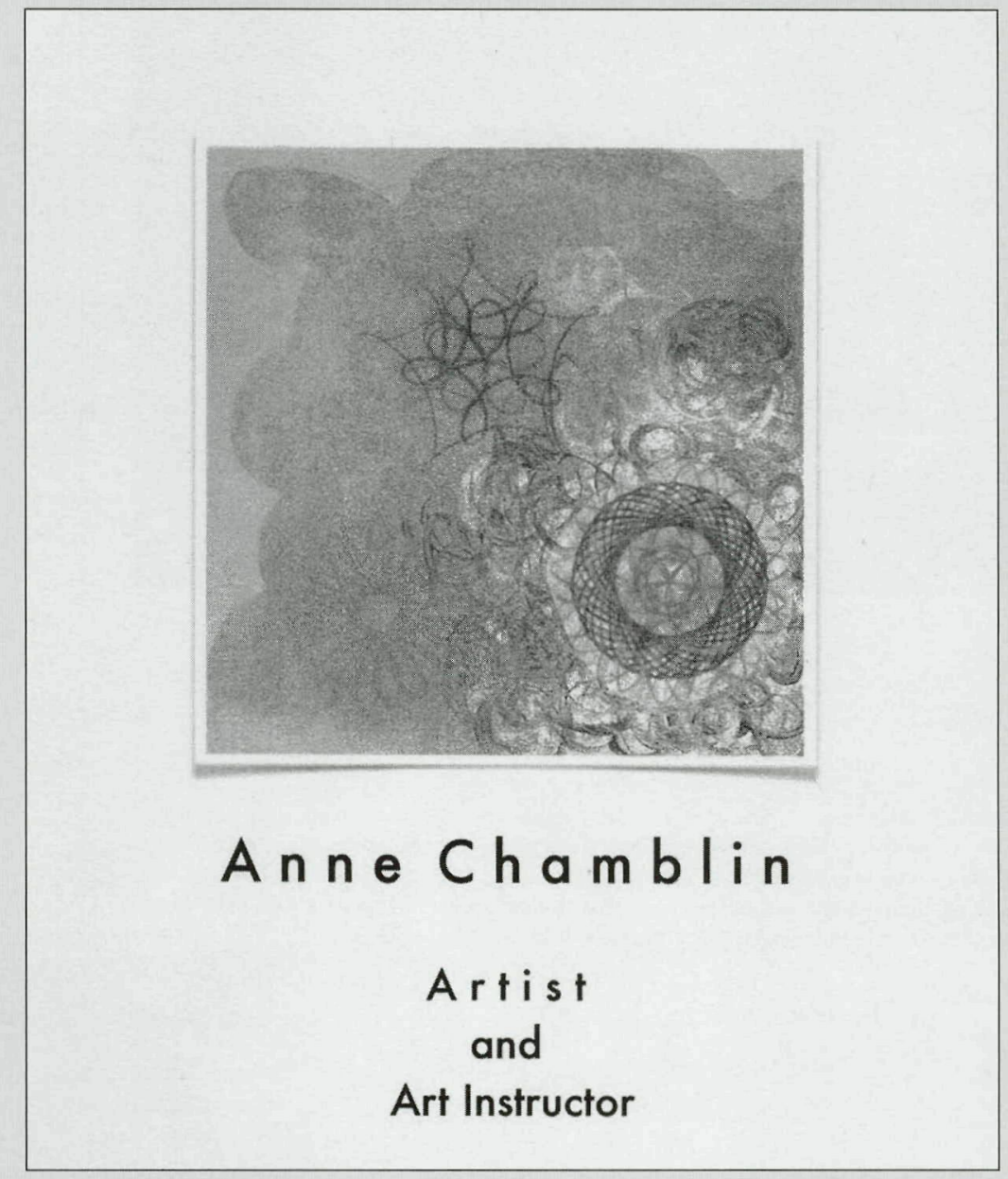

Image of a cover page showing a personal work of art. This job applicant chose to consistently use images of her work on the divider pages throughout her portfolio.

\section{What about an electronic teaching portfolio?}

Though an electronic teaching portfolio is an excellent addition to a hard copy portfolio, according to the respondents of this survey, it should not be viewed as a replacement for a professional teaching portfolio. Of the supervisors surveyed, 75\% said they preferred a job applicant to bring a hard copy of a portfolio to the interview. The reasons the supervisors offered for this included that they might not be able to have a computer or Internet access during the interview and that the use of technology may distract from the interview process. One supervisor indicated that, "Our interview committees are rather large and numbers of interviews are also significant. It is easier to pass around a portfolio than other options. It also provides insight to 'a teachable moment' using the portfolio."
Of the curriculum supervisors who responded to the survey, $15 \%$ indicated that they prefer that art teacher applicants provide a link to a website for their electronic portfolio and nine percent indicated that they preferred to have applicants give them CD/DVDs of their portfolios. Because the vast majority of supervisors (75\%) indicated a preference for a hard copy professional teaching portfolio, it would be wise for applicants to take a hard copy to an interview and also provide a CD/DVD or link to a website for future viewing. 


\section{Final Suggestions}

Both the content and the presentation of the teaching portfolio are extremely important. A portfolio is not a scrapbook and should not contain everything that an educator has ever done. Instead, it needs to include only high quality lesson and unit plans, images, and documents that represent the best of what the applicant can do. Documents that have grades on them; images that are pixilated, blurry, or small; and incomplete documents are not appropriate. Certainly, lessons or units that were created for a university class or for another school are appropriate, but the formatting needs to change to a professional looking document. Throughout the portfolio, applicants should use color, fonts, capitalization, paper, etc. consistently.

Though an applicant may be interested in an elementary position, the portfolio should not contain 'cute' images. Clip art pictures of children at easels wearing smocks are not professional. Many of the curriculum supervisors indicated that they view unorganized, scrapbook-like, and child-like portfolios as a negative. Additionally, they wrote that poor portfolios included "trite, cutesy, or formulaic images" or "cutesy colors and rainbows." They did not appreciate portfolios that seemed to be "scrapbooking efforts gone bad (cute borders, stickers, etc.) — not organized."

\section{Conclusion}

Because curriculum supervisors expect job applicants to come to interviews with professional teaching portfolios, it is essential that art educators prepare meaningful portfolios for their job search process. Further, as portfolios are frequently a part of preservice teacher preparation programs, it is useful to develop guidelines to assist in the creation of high-quality professional teaching portfolios. In this article I offered suggestions for job applicants to create portfolios based upon the results of a survey of art curriculum supervisors and my experiences working with preservice teachers as they prepare for their job searches. Because the sample size was small, I put these ideas forth as suggestions, rather than as absolute conclusions. However I suggest that we, as a field, spend more time investigating the development and use of professional teaching portfolios as a tool for the interview process and beyond.

Melanie L. Buffington is Assistant Professor of Art Education at Virginia Commonwealth University, Richmond. E-mail:mbuffington@vcu.edu
Bain, C. (2005). The secret to obtaining the keys to the art room: Preparing for a successful interview. Art Education, 58(2), 6-11.

Buffington, M. L., \& Lai, A. (2006). Academic job searches. NAEA Advisory. Reston, VA: National Art Education Association.

Bullock, A. A., \& Hawk, P. P. (2000). Developing a teaching portfolio. Upper Saddle River NJ: Merrill Prentice Hall.

\section{REFERENCES}

Campbell, D. M., Cignetti, P. B. Melenyzer, B. J., Nettles, D. H., \& Wyman, R. M. (2007). How to develop a professional portfolio. Boston, MA: Pearson.

Constantino, P. M., \& De Lorenzo M. N. (2006). Developing a professional teaching portfolio: A guide for success. Boston, MA: Pearson.

Kimball, M. A. (2003). The web portfolio guide. New York, NY: Longman.

Roberts, T. (2005). Teaching real artmaking. Art Education, $58(2), 40-45$.
Seldin, P. (2004). The teaching portfolio. Boston, MA: Anker.

Walker, S. R. (2001). Teaching meaning in artmaking. Worcester, MA: Davis.

Wyatt, R. L., \& Looper, S. (2004). So you have to have a portfolio. Thousand Oaks, CA: Corwin Press.

\section{ENDNOTE}

1 Because of privacy concerns, it is essential that professional teaching portfolios do not include students' last names or recognizable images of their faces unless their parents have provided written permission. Many school districts have policies about parental permission and image releases. Before taking photographs of students or student artwork, it is important to consult and follow school policies.

\section{Earn $\$ 500+$ per day}

ART+TEACHING=BUSINESS Start Your Own Sketching Tour Business Nantucket Artist/teacher Anne Sutherland combined a public school teaching background and artistic ability into a fun, successful and very rewarding summer business. It is still thriving 2000 students and 14 years later. Anne offers a week-long training program giving you all the tools you need to start your own business in your town.

\section{5/22-29 6/12-19 7/24-31 8/21-28}

www.sketchingtours.com

annesutherlandart@me.com

Training Week in Nantucket including accommodations and painting studio use

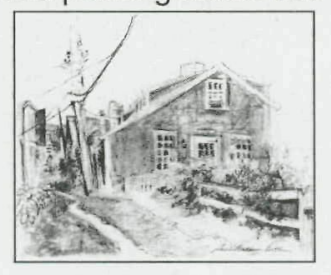

